\title{
Dynamic Spillover Effects between the US Stock Volatility and China's Stock Market Crash Risk: A TVP-VAR Approach
}

\author{
Ping Zhang $\mathbb{D}^{1}{ }^{1}$ Jieying Gao, ${ }^{2}$ Yanbin Zhang, ${ }^{1}$ and Te-Wei Wang $\mathbb{D}^{3}$ \\ ${ }^{1}$ Department of Financial Engineering, School of Finance, Capital University of Economics and Business, Beijing 100070, China \\ ${ }^{2}$ Department of Finance, School of Finance, Capital University of Economics and Business, Beijing 100070, China \\ ${ }^{3}$ Department of MIS, College of Business and Management, University of Illinois, Springfield, IL, USA
}

Correspondence should be addressed to Ping Zhang; zhangping@cueb.edu.cn

Received 22 December 2020; Revised 18 March 2021; Accepted 29 March 2021; Published 10 April 2021

Academic Editor: Shigeyuki Hamori

Copyright ( 92021 Ping Zhang et al. This is an open access article distributed under the Creative Commons Attribution License, which permits unrestricted use, distribution, and reproduction in any medium, provided the original work is properly cited.

Due to the increasing linkage of China and the US stock markets today, we constructed a TVP-VAR model to study the dynamic spillover effects between the US stock volatility and China's stock market crash risk. We found dynamic spillover effects are constantly strengthening between US stock volatility and China's stock market crash risk: when the US stock volatility increases, China's stock market crash risk increases. In addition, the gradual improvement of financial market openness in China, the shortterm capital outflow from China, and the depreciation of the RMB exchange rate will increase China's stock market crash risk. And, the impacts of short-term capital outflow from China are more significant. Further, the increase in China's stock market crash risk will lead to the decline of the US stock volatility, which may be due to the flight to quality.

\section{Introduction}

The US and China are the two largest economies in the world today. There are already significant differences between the two countries in many aspects of the economic field, but the linkage of the two countries' financial markets has gradually increased. Influenced by the trade war between the US and China in 2018, China and the US's stock market had a more than 3\% daily decline numerous times, which triggered panic in the global financial market. As an important phenomenon in the stock market, stock market crash risk will bring loss to investors and affect financial market stability. The stock market crash risk is one of the important factors which threaten the financial market stability. In 2019, the US government restarted the more stringent trade policy with China, further increasing the economic uncertainty between China and the US. How the US stock market's volatility affects China's economy, especially the impact on China's stock market crash risk, has become an important research topic.

In recent years, China has been accelerating the reform of the financial market. The opening of the financial market is important to improve China's stock market's investor structure and efficiency. However, the financial market's opening will also increase the linkage between China's financial market and the international market, aggravate the fluctuation of the financial market, which may lead to systemic risk in the financial system, and then affect the stable development of the economy. Therefore, this paper studies the spillover effects between US stock volatility and China's stock market crash risk in the context of the financial market opening. The analysis of this problem will help us understand the relationship between the two stock markets to prevent China's stock market crash risk caused by US stock volatility.

In this paper, we use the Shanghai Composite Index from January 2000 to January 2019 to calculate the negative coefficient of skewness (NCSKEW) and the down-to-up volatility (DUVOL) as proxy variables of China's stock price crash risk and volatility of the S\&P 500 Index for the volatility of US stock market. Simultaneously, considering the openness of China's financial market, this paper focuses on the impact of short-term capital flow and RMB exchange rates on China's stock price crash risk. Under the financial 
market opening condition, this paper uses the TVP-VAR model to study the dynamic spillover effects between US stock volatility and China's stock market crash risk by the time-varying impulse responses. We find that the US stock market's volatility has an obvious time-varying impact on China's stock market crash risk, and the impact is gradually increasing. When the US stock market fluctuates significantly, China's stock market crash risk increases, and the short-term impact is bigger than the long-term impact. Meanwhile, with the opening of the financial market, China's stock market crash risk increases due to the decrease of short-term capital flow, the devaluation of the RMB exchange rate, and the impact of short-term capital flow are more significant. Finally, we further use the CSI 300 Index and the Dow Jones industrial average for robust tests and obtain consistent conclusions.

As a widespread and influential risk factor in the financial market, crash risk is one of the main risks focused on by all market participants. This paper's marginal contribution is mainly in the following aspects: first, the negative coefficient of skewness (NCSKEW) and the down-to-up volatility (DUVOL) are used as proxy variables of China's stock price crash risk. Second, the dynamic spillover effects between US stock volatility and China's stock market crash risk are studied regarding the financial market opening and finds that the US stock volatility significantly affects China's stock market crash risk. Meanwhile, the decrease of shortterm capital flow and the RMB exchange rate's devaluation will increase China's stock market crash risk, and the impact of short-term capital flow is more significant. Third and lastly, the TVP-VAR model is used to study the dynamic spillover effects between US stock volatility and China's stock market crash risk. All parameters of the TVP-VAR model are time-varying so that it can capture dynamic relationships over time.

The remainder of the study is structured as follows: Section 2 provides a brief literature review. Section 3 discusses the methodology. Section 4 describes the data and conducts preliminary analyses. Section 5 discusses the empirical results. Section 6 concludes the study.

\section{Literature Review}

Crash risk is essentially an extreme risk or tail risk. Rietz [1] proposed that the determinant of equity risk premium is the assumption of rare disasters, including economic recession and war. Barro [2] found that the high equity risk premium is due to the frequent occurrence of extreme events from a global perspective. Bollerslev and Todorov [3] found that the equity risk premium is compensation for rare events. Gabaix [4] found that when a disaster occurred, asset prices' fundamental value decreased with time, resulting in a time-varying risk premium. Gennaioli et al. [5] found that investors are more worried about future crash risk when there is a recent crash risk. Kelly and Jiang [6] proposed dynamic power law to measure tail risk from the left tail distribution of asset price. They estimated the dynamic power law using daily asset returns. Then, they found that abnormal asset return is high when the tail risk is high. Based on the extreme value theory, Van Oordt and Zhou [7] assumed the return followed a fat-tailed distribution and used asset prices' sensitivity to an extreme crash event to measure tail risk. They found that tail risk could predict asset returns, and when the stock market crash occurred, assets with high tail risk had more losses. ChabiYo et al. [8] used low tail dependence based on the copular method to measure stock crash risk sensitivity and found that stocks with high tail risk have higher expected returns than stocks with low tail risk. This effect could not be explained by traditional risk factors, beta, downside beta, coskewness, cokurtosis, and tail beta. Extreme events often lead to a sharp decline in investor' wealth, and investors who have crash aversion will require higher risk compensation for those stocks that are more prone to crash in a crisis. The existing literature studies the stock market crash risk from the microperspective and not from the macroperspective. This paper studies the relationship between US stock volatility and China's stock market crash risk from the macroperspective.

Diamandis [9] found that Argentina, Chile, Brazil, and Mexico have a strong linkage with the US stock market. Korkmaz et al. [10] studied the spillover effects between the markets of Colombia, Vietnam, Turkey, South Africa, Indonesia, and Egypt. Li and Zhang [11] used the Dow Jones Index and Shanghai Composite Index from 2005 to 2013 to study the spillover effects and resonance effect of the stock market in China and the US. Since the subprime mortgage crisis in 2008, the US stock market has a short-term one-way spillover effect on China's stock market. The US stock market's price change can predict the price of China's stock market, but there is no volatility spillover effect between China and the US. Hou and Li [12] used the S\&P 500 and CSI 300 stock index futures from 2010 to 2013 and found there was a mutual influence between volatility and the influence of the US stock market on China's stock market was more obvious. Asgharian et al. [13] used spatial econometrics to study the impact of economic and geographical relations on stock market linkage and found that the linkage of the stock market gradually increased, the role of bilateral trade on stock market linkage increased, and the role of distance on stock market linkage weakened. Mensi et al. [14] used a quantile regression method to study the influence of global economic factors, such as commodity price, US policy uncertainty, and stock market uncertainty (VIX on BRICS stock market). The study found that the uncertainty of commodity price and the US stock market would affect the BRICS stock market, but the US policy uncertainty did not affect it. Diebold and Yilmaz [15] studied the stock market returns and volatility spillover effects in 19 countries, which showed a slow-growth trend in return, and the volatility spillover effect can predict the crisis. Chevallier et al. [16] applied Diebold and Yilmaz [15, 17] spillover model to study the spillover effects among 14 countries and found that the spillover effects of developed countries were more significant; however, the interdependence of the ASEAN stock market increased due to financial development and globalization. They found that the Asia Pacific region had become increasingly interconnected across markets, which 
could reduce the benefits of regional diversification strategies and expose risk contagion. Yang and Hamori [18] find US interest rates have a negative effect on the selected ASEAN stock markets during expansion, and ASEAN stock markets have a positive comovement with the US stock market in both regimes. Existing literature mainly studies the spillover effect between China and US stock markets from risk spillover. This paper focuses on the impact of US stock volatility on China's stock market crash risk and its dynamic spillover effects.

Financial development and globalization have increased the level of integration of the global stock market. $\mathrm{RMB}$ exchange rates and short-term capital flow are important parts of financial opening, which play a vital role in the stock market. Koulakiotis et al. [19] used the asymmetric threshold method to demonstrate the relationship between the US, Canada, and the UK exchange rates and stock markets. They found there was a causal relationship between both. Bahmani-Oskooee and Saha [20] used a nonlinear ARDL method of the Cointegration and Error Correction Model to analyze the impact of exchange rates on nine countries' stock markets in the UK, Japan, Canada, and so forth. They found that the impact of the exchange rate on the stock market was asymmetric. Sui and Sun [21] found stock return had a spillover effect between US and BRIC countries, and the short-term foreign exchange rate had significant spillover effects on stock return. Morales-Zumaquero and SosvillaRivero [22] used the C-GARCH and SVAR methods to study the volatility spillover effects between the stock market and the foreign exchange market. They found that the stock market played a leading role in volatility transmission, and the foreign exchange market was the main reason for the long-term volatility of the stock market. Kim and and Iwasawa [23] found the more shortterm capital flowed into the stock before the crisis, the more prices declined during the crisis, which led to the stock market's instability. Wei et al. [24] applied the nonlinear Granger causality test and GARCH-MIDAS model and found no linear or nonlinear causality between the growth rate of hot money and China's stock market return. Their results indicate that China's stock market was not driven by hot money; however, hot money had a significant positive impact on Cina's stock market's longterm volatility. The dependence between the long-term volatility caused by hot money and the total volatility of China's stock market is time-varying. Taguchi et al. [25] studied the impact of capital flows on stock prices in different monetary systems. They found the external capital flows directly impacted stock prices, except in the transition economy. Capital inflow can also indirectly increase the stock price by increasing the base money, but it only worked under the peg regime, not under the floating regime. Barroso et al. [26] found that the US unconventional monetary policy affected Brazil's capital inflow, which channeled to exchange rate appreciation, stock market price rise, credit growth, and consumption increase. Gyntelberg et al. [27] studied the capital inflow of foreign investors into the stock market had a significant impact on the exchange rate, while the capital inflow into the local government bond market had no impact on the exchange rate. From the above, the RMB exchange rate and short-term capital flow have a great impact on the stock price (return or volatility), so this paper puts them into the model of stock market crash risk. Most existing studies are focused on the pairwise relationship between the RMB exchange rate, capital flow, and stock price, and the relationship among them is concentrated upon the direction of international capital flow. Limited studies are related to stock market crash risk. This paper studies the impact of US stock volatility on China's stock market crash risk under the condition of the financial market opening.

\section{Methodology}

In this paper, the TVP-VAR model is used to study the spillover effects between US stock volatility and China's stock market crash risk. VAR model was first proposed by Sims [28] and became a standard econometric model in macroeconomic literature. However, the hypothesis of its fixed parameters made its explanatory power greatly constrained, and scholars gradually improved this deficiency. Cogley and Sargent [29] proposed a VAR model with timevarying coefficients, but the variance and covariance are constrained. Later, Cogley and Sargent [30] put stochastic volatility into the VAR model with time-varying coefficients but still assumed that the synchronous relationship between variables was constant. Primiceri [31] developed the VAR model into a TVP-VAR model with time-varying intercept, coefficient, variance, and covariance. Subsequently, the model with time-varying coefficients and variances has been widely used in macroeconomic research [32-34]. The TVP-VAR model is briefly introduced below.

3.1. VAR Model. The basic structural VAR model defined as

$$
A y_{t}=F_{1} y_{t-1}+F_{2} y_{t-2}+\cdots+F_{s} y_{s-1}+u_{t}, \quad t=s+1, \ldots, n,
$$

where $y_{t}$ is the $k \times 1$ vector of observed variables, and $A, F_{1}$, $\ldots, F_{s}$ are $k \times k$ matrix of coefficients. $u_{t}$ is a $k \times 1$ structural shock. By Nakajima et al. [35], we specify the simultaneous relations of the structural shock by recursive identification, assuming that $A$ is lower triangular:

$$
A=\left(\begin{array}{cccc}
1 & 0 & \ldots & 0 \\
a_{21} & 1 & \ldots & 0 \\
\vdots & \vdots & \ddots & \vdots \\
a_{k 1} & \ldots & a_{k, k 1-1} & 1
\end{array}\right) .
$$

We rewrite model (1) as the following reduced-form VAR model:

$$
y_{t}=B_{1} y_{t-1}+B_{2} y_{t-2}+\cdots+B_{s} y_{s-1}+A^{-1} \sum \varepsilon_{t}, \quad \varepsilon_{t} \sim N\left(0, I_{k}\right),
$$

where $B_{i}=A^{-1} F_{i}, i=1,2,3, \ldots, s$, and 


$$
\sum=\left(\begin{array}{cccc}
\sigma_{1} & 0 & \ldots & 0 \\
0 & \sigma_{2} & \ldots & 0 \\
\vdots & \vdots & \ddots & \vdots \\
0 & \ldots & \ldots & \sigma_{k}
\end{array}\right) .
$$

$\sigma_{i}(i=1, \ldots, k)$ is the standard deviation of the structural shock. Stacking the elements in the rows

of the $B_{i}(i=1, \ldots, s)$ to form $\beta$, which is $s k^{2} \times 1$ vector, and defining $X_{t}=I_{k} \otimes\left(y_{t-1}^{\prime} \ldots y_{t-k}^{\prime}\right)$, the model can be written as

$$
y_{t}=X_{t} \beta+A^{-1} \sum \varepsilon_{t} .
$$

All parameters in equation (5) are time-invariant. In the next section, we construct the model by allowing these parameters to vary over time.

3.2. Time-Varying Parameter VAR. We consider a timevarying parameter VAR (TVP-VAR) model specified by

$$
y_{t}=X_{t} \beta_{t}+A_{t}^{-1} \sum_{t} \varepsilon_{t}, \quad t=s+1, \ldots, n,
$$

where the coefficients $\beta_{t}$, the parameters $A_{t}$, and $\Sigma_{t}$ are all time-varying. We can consider many ways to model the process for these time-varying parameters. Let $a_{t}$ be a stacked vector of the lower triangular elements in $a_{t}$ and $h_{t}=\left(h_{1 t}, \ldots, h_{k t}\right)^{\prime}$ with $h_{1 t}=\log \sigma_{j t}^{2}$ for $j=1, \ldots, k$, and $t=s+1$, $\ldots, n$. As suggested by Primiceri [31], we assume that the parameters in (6) follow a random-walk process as follows:

$$
\left.\begin{array}{l}
\beta_{t+1}=\beta_{t}+u_{\beta t} \\
a_{t+1}=a_{t}+u_{a t}
\end{array} \quad \begin{array}{l}
h_{t}+u_{h t} \\
u_{t+1} \\
u_{a t} \\
u_{h t}
\end{array}\right) \sim N\left(0,\left(\begin{array}{cccc}
I & 0 & 0 & 0 \\
0 & \sum_{\beta} & 0 & 0 \\
& \beta & & \\
0 & 0 & \sum_{a} & 0 \\
0 & 0 & 0 & \sum_{h}
\end{array}\right)\right)
$$

for $t=s+1, \ldots, n$, where $\beta_{s+1} \sim N\left(u_{\beta 0}, \Sigma_{\beta 0}, a_{\mathrm{s}+1} \sim N\left(u_{a 0}, \Sigma_{a 0}\right)\right.$ and $h_{s+1} \sim N\left(u_{h 0}, \Sigma_{h 0}\right)$. The shocks to the innovations of the time-varying parameters are assumed uncorrelated among the parameters $\beta_{t}, a_{t}$, and $h_{\mathrm{t}}$. We further assume that $\Sigma \beta, \Sigma a$, and $\Sigma h$ are all diagonal matrices. The drifting coefficients and parameters are modeled to fully capture possible changes of the VAR structure over time. Moreover, as discussed by Primiceri [31], the random-walk assumption can capture possible gradual (or sudden) structural change in stochastic volatility.

\section{Data and Summary Statistics}

4.1. Data Source and Sample. The stock market crash is calculated with returns of the Shanghai Composite Index and CSI 300 Index. The US stock market's volatility is estimated with the return of S\&P 500 index (SPR) and the return of Dow Jones industrial average (DJIAR) by the
GARCH model. We obtain S\&P 500 volatility (SPV) and Dow Jones industrial average volatility (DJIAV). The capital flow is the short-term international capital flow to China. We select the average exchange rate of RMB to USD. The sample period is from January 2000 to December 2019. All data is from the CSMAR, Wind, CEInet Statistics Database.

4.2. Stock Price Crash Risk. We measure stock price crash risk, following Chen et al. [36] and Kim et al. [37, 38], with the negative coefficient of skewness (NCSKEW) and downto-up volatility (DUVOL). Some adjustments and optimizations are made to calculate the two variables. First, we define the market return as $W_{t}=\ln \left(1+R_{t}\right)$, where $R_{t}$ is the Shanghai Composite Index on $t$ day. The negative coefficient of skewness (NCSKEW) is the ratio of the third moment of stock market returns over the standard deviation of stock market returns raised to the third power and then multiplied by -1 , as shown below:

$$
\operatorname{NCSKEW}_{t}=\frac{n(n-1)^{3 / 2} \sum_{\tau} W_{\tau}^{3}}{(n-1)(n-2)\left(\sum_{\tau} W_{\tau}^{2}\right)^{3 / 2}},
$$

where $n$ is the trading days of stock Index in month $t$. Adding a negative sign on the right side of the equation will make the negative coefficient of skewness positively correlate with the stock price crash. In other words, the higher the negative skewness coefficient is, the higher the stock price crash risk is.

We calculate the down-to-up volatility (DUVOL) as

$$
\mathrm{DUVOL}_{t}=\ln \frac{\left(n_{\text {up }}-1\right) \sum_{\text {down }} W_{\tau}^{2}}{\left(n_{\text {down }}-1\right) \sum_{\text {up }} W_{\tau}^{2}}
$$

where $n_{u p}$ and $n_{\text {down }}$ are the up and down days. For returns in month $t$, we separate all the days with returns below the monthly mean (down days) from those with returns above the monthly mean (up days) and calculate the standard deviation for each of these subsamples separately. Then, the DUVOL measure is the log of the ratio of the standard deviation of the down days to the standard deviation of the up days. An increase in DUVOL corresponds to a stock being more likely to crash and vice versa.

4.3. Descriptive Statistics. The descriptive statistics are listed in Table 1. From Table 1, we find the median and mean of the negative coefficient of skewness (NCSKEW) and down-to-up volatility (DUVOL) were all larger than 0 , which described that from January 2000 to December 2019, the overall distribution of stock market returns in China skewed to the left, and the extreme decline was common.

4.4. Correlations. The correlations are listed in Table 2. From Table 2, we find the negative coefficient of skewness (NCSKEW) and down-to-up volatility (DUVOL) have a strong correlation, and the correlation coefficient is 0.955 , which shows the two indicators are consistent in measuring the stock price crash risk. In addition, there is a negative 
Table 1: Descriptive statistics.

\begin{tabular}{lccccc}
\hline Variable & Mean & Median & Max & Min. & Std. dev. \\
\hline NCSKEW & 0.0460 & 0.0403 & 2.8567 & -2.7810 & 1.0706 \\
DUVOL & 0.0362 & 0.0890 & 3.3012 & -3.2811 & 1.2063 \\
CF & -10.2659 & -3.1964 & 34.9066 & -117.1541 & 24.8748 \\
E & 7.1976 & 6.8480 & 8.2795 & 6.1043 & 240 \\
SPR & 0.4620 & 0.7611 & 10.6047 & -14.0604 & 240 \\
DJIAR & 0.4174 & 0.9598 & 10.7723 & -16.9425 & 4.0458 \\
SPV & 3.9364 & 3.5800 & 8.1291 & 2.4051 & 4.1840 \\
DJIAV & 4.0053 & 3.5626 & 9.9925 & 2.1000 & 1.1631 \\
\hline
\end{tabular}

TABLE 2: Correlations.

\begin{tabular}{|c|c|c|c|c|c|c|c|c|}
\hline & NCSKEW & DUVOL & $\mathrm{CF}$ & E & SPR & DJIAR & SPV & DJIAV \\
\hline NCSKEW & 1.000 & & & & & & & \\
\hline DUVOL & $0.947^{* * *}$ & 1.000 & & & & & & \\
\hline $\mathrm{CF}$ & -0.003 & 0.039 & 1.000 & & & & & \\
\hline $\mathrm{E}$ & -0.014 & 0.004 & $0.371^{* * *}$ & 1.000 & & & & \\
\hline SPR & $-0.163^{* *}$ & $-0.165^{* *}$ & 0.030 & -0.064 & 1.000 & & & \\
\hline DJIAR & $-0.180^{* * *}$ & $-0.180^{* * *}$ & 0.034 & -0.089 & $0.956^{* * *}$ & 1.000 & & \\
\hline SPV & -0.004 & -0.006 & $0.145^{* *}$ & $0.128^{* *}$ & 0.030 & 0.030 & 1.000 & \\
\hline DJIAV & -0.015 & -0.027 & $0.143^{* *}$ & 0.084 & -0.024 & -0.023 & $0.960^{* * *}$ & 1.000 \\
\hline
\end{tabular}

${ }^{* * *} p<0.01,{ }^{* *} p<0.05,{ }^{*} p<0.1$.

correlation between China's stock market crash risk and the US stock volatility and a positive correlation between shortterm capital inflow and exchange rate and US stock volatility.

4.5. Unit Root ADF Test. The unit root ADF test results are listed in Table 3 . In the following research, stable variables will be used for model construction.

\section{Results and Discussions}

Next, we use the negative coefficient of skewness NCSKEW, short-term capital inflow $\mathrm{CF}$, the difference of the exchange rate $\Delta E$, and S\&P 500 volatility SPV to construct the TVPVAR model and analyze the dynamic spillover effect of US stock volatility on China's stock market crash risk. The VAR model lag order is 1 , which is determined by AIC and SC criteria.

5.1. Parameter Estimation Results and Validation of MCMC Algorithm. We estimate the TVP-VAR model by OxMetrics 6. The sample of the MCMC algorithm is set to 10000, and the initial 1000 samples are discarded. Table 4 and Figure 1 report the estimation results for the selected parameters of the TVP-VAR model. The results show that the MCMC algorithm produces posterior draws efficiently. Table 4 provides the estimates for posterior means, standard deviations, the $95 \%$ credible intervals, the CD of Geweke [39]; and the inefficiency factors. From Table 4, we find the null hypothesis of the convergence to the posterior distribution is not rejected for the parameters at the 5\% significance level based on the CD statistics. The inefficiency factors are very low. All of them are less than 100, which indicates an efficient sampling for the parameters in the TVP-VAR model. Figure 1 shows the sample autocorrelation function, the sample paths, and the posterior densities for selected parameters. From Figure 1, we find the sample paths look stable, and the sample autocorrelations drop stably, indicating our sampling method efficiently produces uncorrelated samples.

5.2. Time-Varying Volatility. The TVP-VAR model focuses on the analysis of coefficients and variances that change with time. Heteroscedasticity is an important feature of the TVPVAR model, which is different from the other VAR models. Figure 2 shows the stochastic volatilities of the four variables. In 2001, 2005, 2007, 2010, 2015, and 2018, the stochastic volatility of stock market crash risk has great volatility. The S\&P 500 SPV's stochastic volatility fluctuated significantly in 2001, 2003, 2007, 2018, and slightly in 2010. The stochastic volatility of short-term capital flow fluctuated greatly after the subprime mortgage crisis in 2007, and the stochastic volatility of the exchange rate fluctuated greatly after China's stock market crash in 2015. All pivotal events are the US IT bubble in 2001, the reform of China's exchange rate system in 2005, the subprime mortgage crisis in 2007, the US stock market crash in 2010, the 2015 China stock market crash in 2015, and the US-China trade war in 2018.

\subsection{Analysis and Results of Impulse Response at Different Time} Points. We choose 8-time points to study the dynamic spillover effects between US stock volatility and China's stock market crash risk through internal and external shock. The external shocks are the events that had significant influences on the stock markets globally, especially the US stock market, while the internal shocks are the events that 
TABLE 3: Unit root ADF test results.

\begin{tabular}{lccccc}
\hline Variable & ADF & $1 \%$ & $5 \%$ & $P$ & Conclusion \\
\hline NCSKEW & -7.0362 & -3.4591 & -2.8741 & $p \leq 0.001$ & Stable \\
DUVOL & -14.5749 & -3.4590 & -2.8740 & $p \leq 0.001$ & Stable \\
CF & -3.5315 & -3.4591 & -2.8741 & $p \leq 0.001$ & Stable \\
$E$ & -1.0883 & -3.4591 & -2.8741 & $p \geq 0.05$ & Unstable \\
$\Delta E$ & -9.6433 & -3.4591 & -2.8741 & $p \leq 0.001$ & Stable \\
SPV & -3.6990 & -3.4590 & -2.8740 & $p \leq 0.01$ & Stable \\
DJIAV & -3.6979 & -3.4590 & -2.8740 & $p \leq 0.01$ & Stable \\
\hline
\end{tabular}

TABLE 4: Estimation results of the selected parameters in the TVPVAR model.

\begin{tabular}{lccccc}
\hline Parameter & Mean & St. dev. & $95 \%$ interval & CD & Inefficiency \\
\hline$\left(\sum_{\beta}\right)_{1}$ & 0.0225 & 0.0025 & {$[0.0182,0.0280]$} & 0.108 & 8.38 \\
$(\mathrm{sb} 1)$ & & & & & \\
$\left(\sum_{\beta}\right)_{2}$ & 0.0224 & 0.0027 & {$[0.0181,0.0286]$} & 0.573 & 14.48 \\
$(\mathrm{sb} 2)$ & & & & & \\
$\left(\sum_{a}\right)_{1}(\mathrm{sa} 1)$ & 0.0403 & 0.0069 & {$[0.0287 .0 .0556]$} & 0.414 & 23.51 \\
$\left(\sum_{a}\right)_{2}(\mathrm{sa} 2)$ & 0.0298 & 0.0037 & {$[0.0236,0.0382]$} & 0.970 & 15.30 \\
$\left(\sum_{h}\right)_{1}$ & 0.1959 & 0.0556 & {$[0.1051,0.3192]$} & 0.795 & 65.17 \\
$(\mathrm{sh} 1)$ & & & & & \\
$\left(\sum_{h}\right)_{2}$ & 0.5750 & 0.1470 & {$[0.3343,0.9001]$} & 0.282 & 58.76 \\
$(\mathrm{sh} 2)$ & & & & & \\
\hline
\end{tabular}

Note. The estimates of $\Sigma_{\beta}$ and $\Sigma_{\alpha}$ are multiplied by 100 .

happened in China or had significant influences on China's stock market.

The time points of external shocks are September 2001, August 2007, May 2010, and October 2018. In September 2001, the US stock market fell sharply due to the $9 / 11$ terrorist attack and the IT bubble. In August 2007, US stocks fluctuated greatly as the subprime mortgage crisis broke out. In May 2010, a trader mistyped millions ( $\mathrm{m}$ ) into billions (b) when he sold stocks, resulting in a sudden drop of nearly 1000 points in the US stock index. In October 2018, due to the Trump government's foreign trade frictions and the China-US trade war, the US stock market had a significant fluctuation.

The time points of internal shocks are July 2005, August 2007, August 2015, and December 2018. On July 21, 2005, the China central bank carried out a major reform of the exchange rate system, making the RMB enter the appreciation channel, and the Shanghai stock index started a bull market. From July 2007 to 2008, the subprime mortgage crisis significantly impacted China's stock market, which led China's stock market to fluctuate dramatically. At the same time, the RMB was pegged back to the dollar. From May to June in 2015, China's stock market plummeted, which had a great shock to the market. On August 11 of the same year, the RMB exchange rate was reformed for the second time, which adjusted the middle quotation mechanism of RMB to the USD exchange rate, further deepened the marketization of the RMB exchange rate, and strengthened the intervention of foreign exchange. Since 2018, the tax reform of the US Trump government and soon after the "trade shock" on China had a great impact on China's macroeconomy, especially the crash of China's stock market on December 28, 2018.
5.3.1. The Impulse Response of External Shock at Different Time Points. The impulse response results of external shocks at different time points are listed in Figure 3. When the shock of the S\&P 500 volatility is positive, except for September 2001, the impulse response of stock market crash risk at three different external shocks points are consistent: all are positive, reach the maximum value at the first or second period, and then decrease to zero gradually.

When the shock of the short-term capital flow is positive, except for September 2001, the impulse responses of stock market crash risk at three different external shock points are consistent, reach the minimum value at the first period, and then increase to zero gradually. When the shock of the RMB exchange rate is positive, the impulse responses of the stock market crash risk at four different time points are all negative, after reaching the minimum value at the first period, the impulse responses increase to zero. When the shock of the S\&P 500 volatility is positive, the impulse responses of short-term capital flows in September 2001 and August 2007 are always positive, but the impulse response of short-term capital flows in May 2010 and October 2018 are still negative. When the shock of the S\&P 500 volatility is positive, the impulse response of the RMB exchange rate changes at September 2001, May 2010, and October 2018 fluctuates around 0 which indicates the impacts are small. Conversely, in August 2007, the impulse response of the RMB exchange rate change is larger and gradually decreased to 0 after reaching the maximum value at the third period. When the shock of stock market crash risk is positive, the impulse responses of the S\&P 500 volatility at August 2007 and May 2010 are the maximum and gradually decrease to 0 . But in September 2001 and May 2018, the impulse responses of the S\&P 500 volatility are the minimum and gradually increase to 0 .

To summarize, from the impulse response analysis of external shocks at different time points, that the US stock volatility will increase China's stock market crash risk reduce the short-term capital flow and devalue the RMB exchange rate. Short-term capital inflow and devaluation of RMB will reduce China's stock market crash risk. It is also found that after the subprime crisis in 2007, the impact of US stock volatility on China's financial market has increased. The China-US trade war in 2018 has had a huge negative impact on China's financial market, which lead to China's stock market plummeting, short-term capital outflow, and the RMB devaluation. And we find China's stock market crash risk has a relatively weak impact on US stock volatility, which may be due to the flight to quality; when China's stock market crash risk increases, investors prefer safe assets.

5.3.2. The Impulse Response of Internal Shock at Different Time Points. The impulse response results of internal shock at different time points are listed in Figure 4 . When the shock of the S\&P 500 volatility is positive, the stock market crash risk at different time points decreases gradually to zero after reaching the maximum at the first period, but impulse response in August 2015 is relatively stable and decreases slowly. When the shock of the short-term capital flows is 

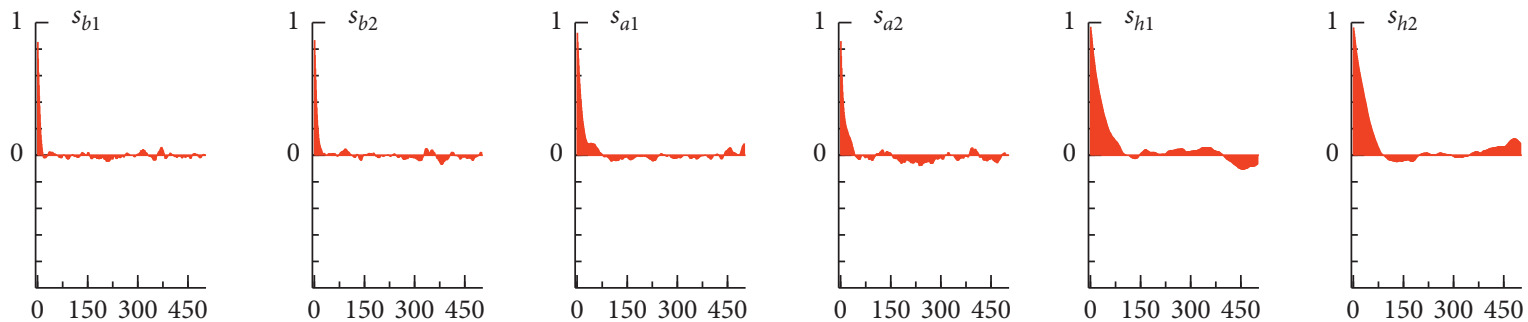

(a)
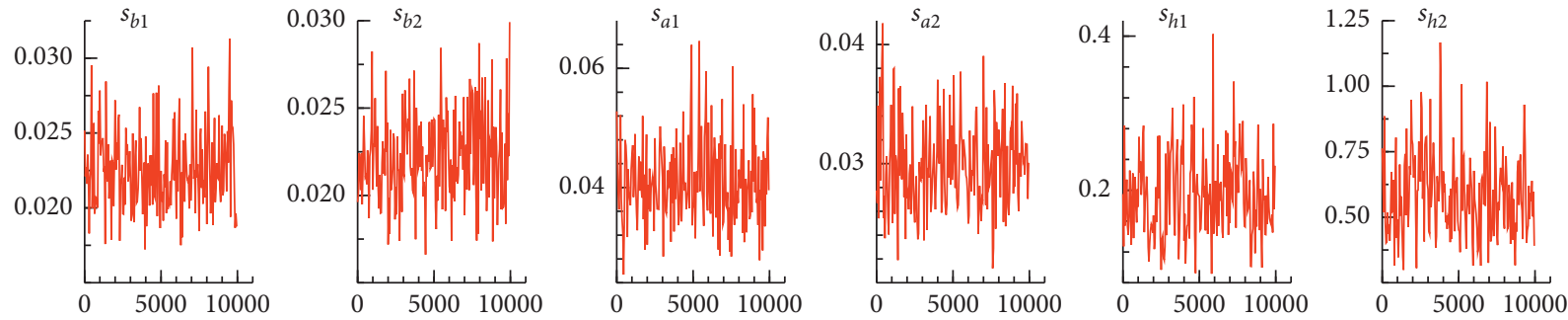

(b)
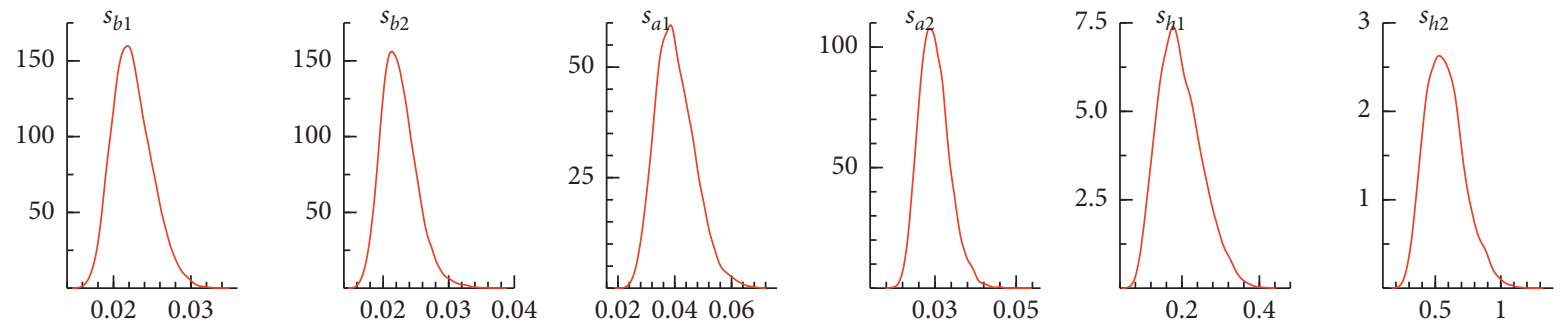

(c)

FIgURE 1: Estimation Results of Selected Parameters in the TVP-VAR Model. Sample autocorrelations (top), sample paths (middle), and posterior densities (bottom).

positive, the stock market crash risk at different time points increases gradually to zero after reaching the minimum value in the first period. When the shock of the RMB exchange rate is positive, the stock market crash risk at different time points increases gradually to zero after reaching the minimum at the first period. When the shock of the S\&P 500 volatility is positive, the impulse responses of short-term capital flow in July 2005 and August 2007 are always positive and gradually decrease to 0 . But the impulse responses in August 2015 and December 2018 are always negative and gradually increase to 0 . When the shock of the S\&P 500 volatility is positive, the impulse responses of the RMB exchange rate in July 2005 and August 2007 change greatly, while in August 2015 and December 2018, there is only a small change. When the shock of stock market crash risk is positive, the impulse responses of the S\&P 500 volatility in July 2005 and August 2007 are the maximum and gradually decrease to 0. However, in August 2015 and December 2018, the impulse responses of the S\&P 500 volatility are the minimum and gradually increase to 0 .

To summarize, from the impulse response analysis of internal shocks at different time points, we can conclude that the US stock volatility will increase China's stock market crash risk, reduce the short-term capital flow, and devalue the RMB exchange rate. Short-term capital outflow and the
RMB exchange rate depreciation will further aggravate China's stock market crash risk. The impact of China's stock market crash risk on US stock volatility changed after the subprime crisis in 2007; China's stock market crash risk will reduce US stock volatility. The internal shock further aggravates China's stock market crash risk through short-term capital outflow and RMB exchange rate depreciation.

5.4. Time-Varying Impulse Responses. The results of timevarying impulse responses are listed in Figure 5. When the shocks of S\&P 500 volatility for 1 month, 3 months, and 5 months ahead are positive, the impulse responses of China's stock market crash risk are highly consistent. They are negative before 2003, increase continuously after 2003, and maintain at a relatively high level in 2012-2018. When the shocks of short-term capital flow and RMB exchange rates for 1 month, 3 months, and 5 months ahead are positive, the impulse responses of China's stock market crash risk are negative and highly consistent. The shock for 1 month ahead will greatly reduce China's stock market crash risk, while for 3 months and 5 months ahead, the shocks have little impact on China's stock market crash risk and are relatively stable. When the shocks of S\&P 500 volatility for 1 month, 3 months, and 5 months ahead are positive, the impulse 


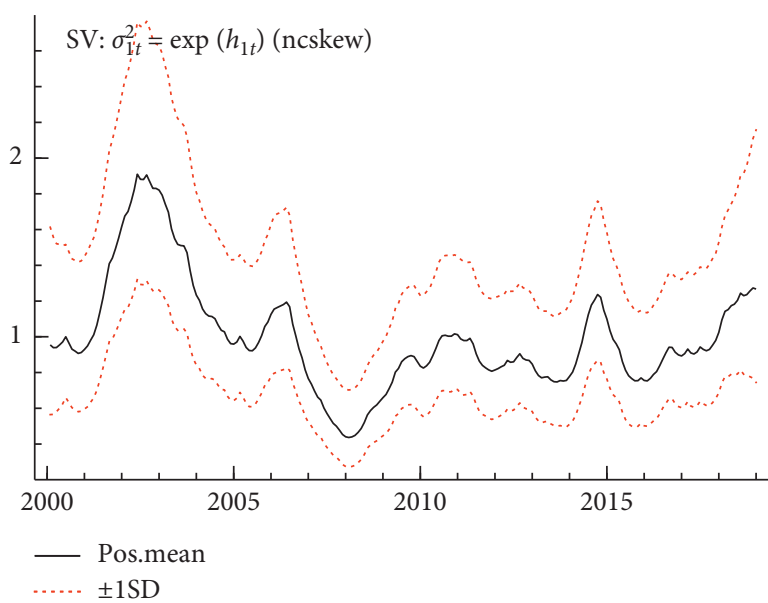

(a)

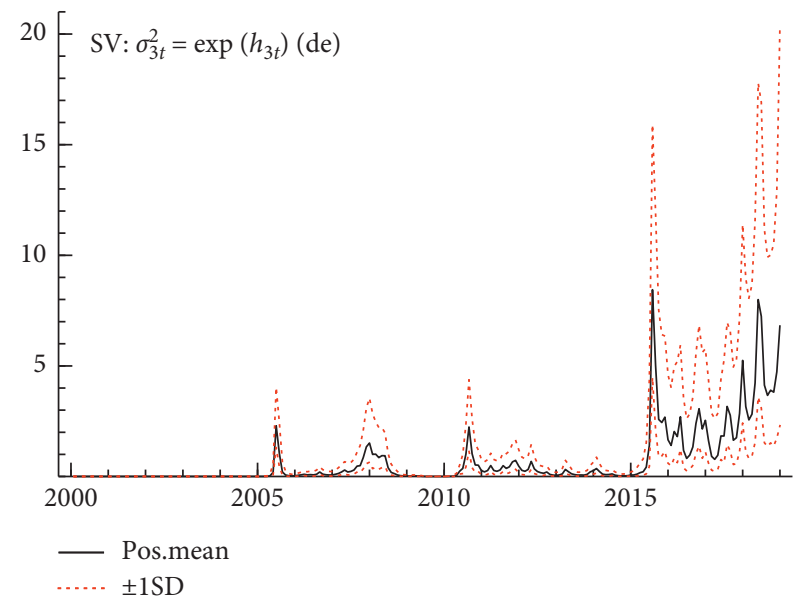

(c)

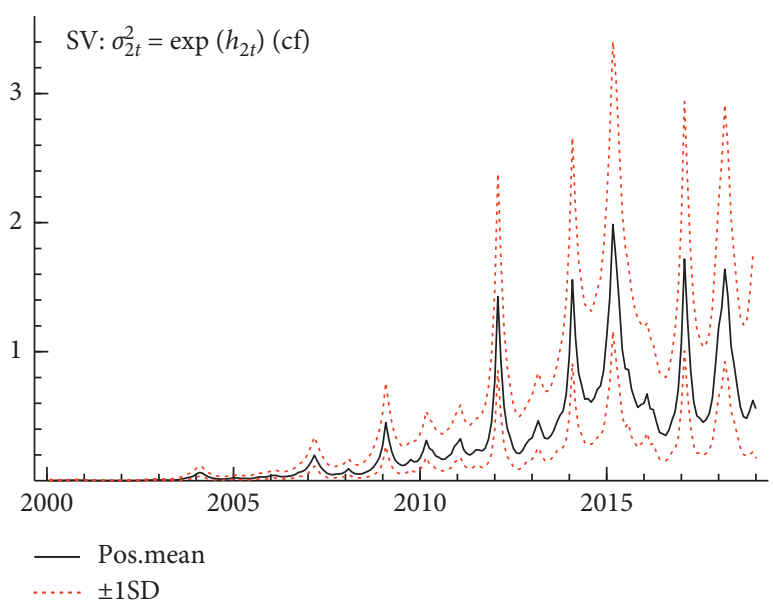

(b)

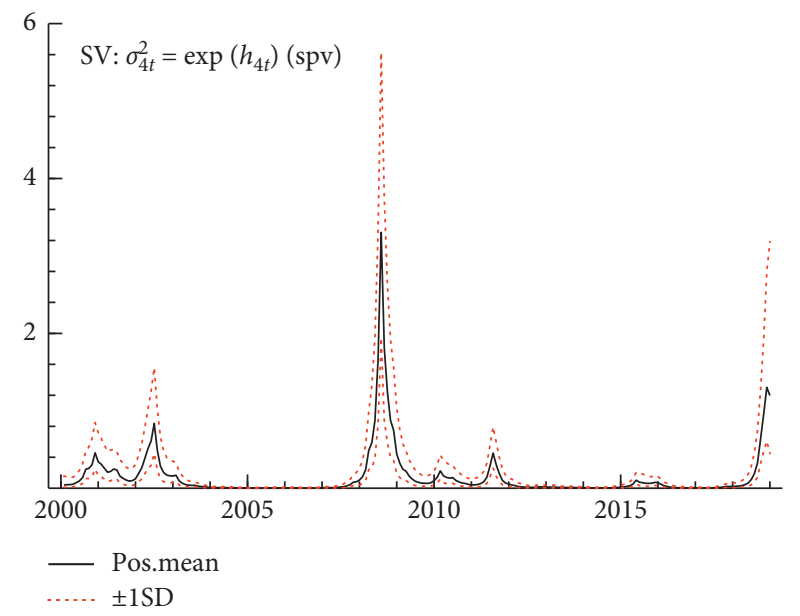

(d)

FIgURe 2: Posterior estimates for stochastic volatility of structural shock.

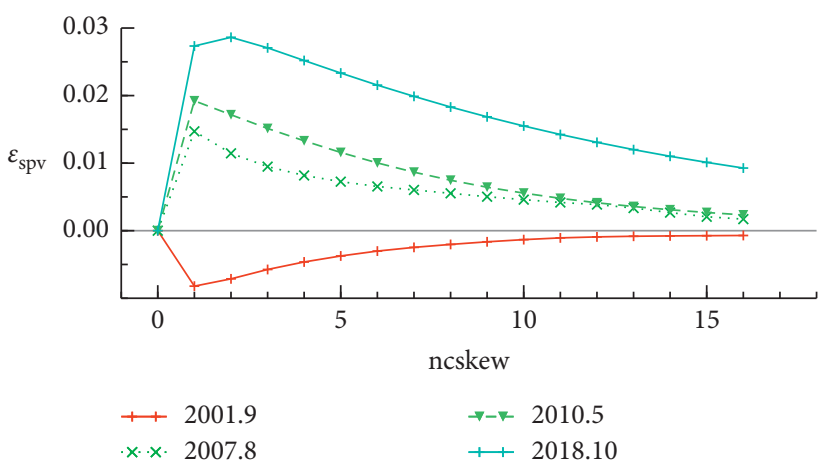

(a)

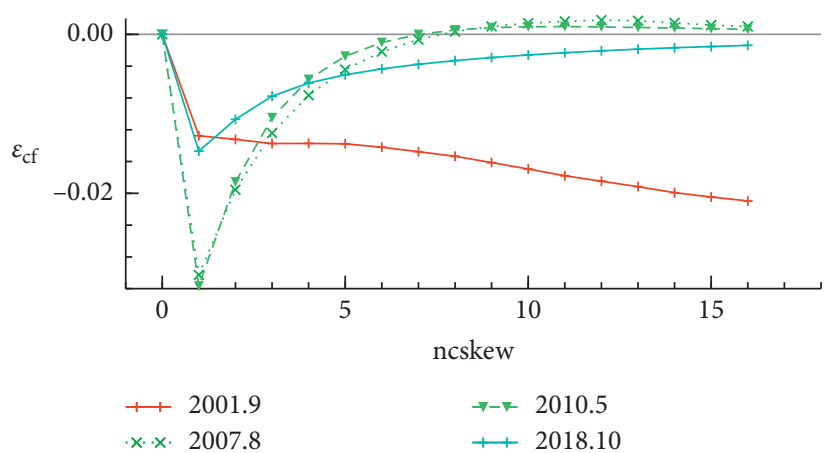

(b)

FIgUre 3: Continued. 

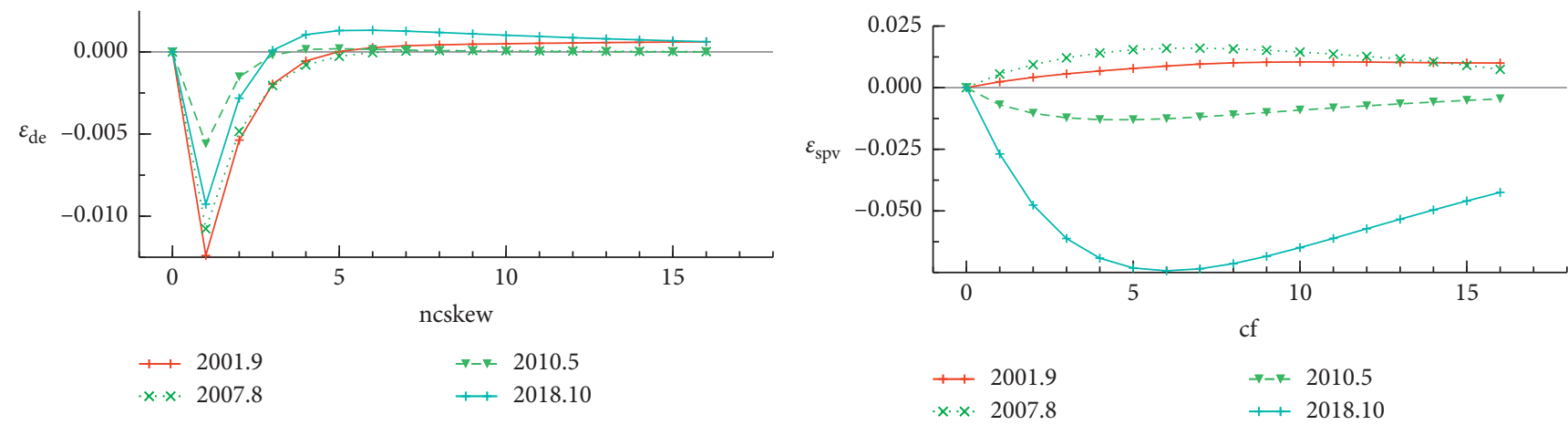

(c)
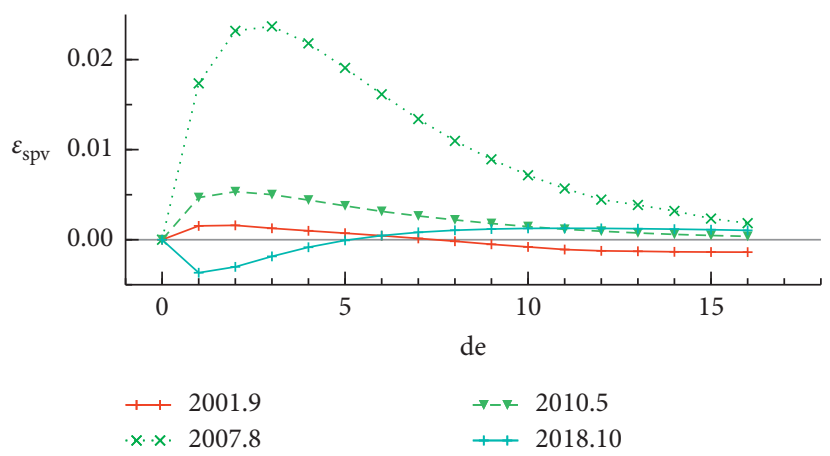

(e)

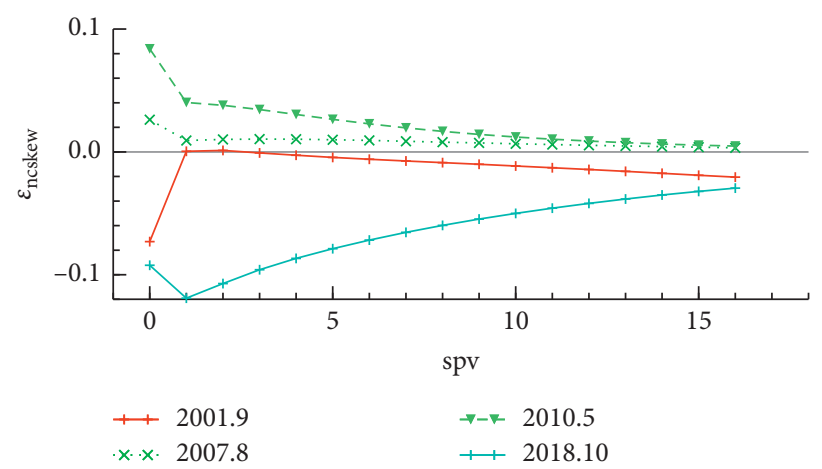

(f)

FIGURE 3: The impulse response of external shock at different time points.
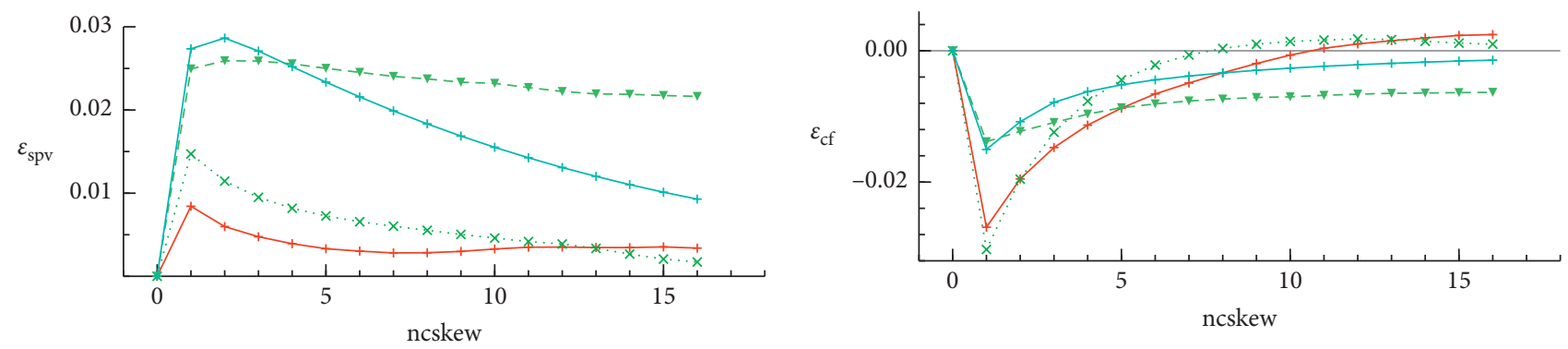

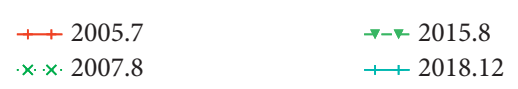

(a)

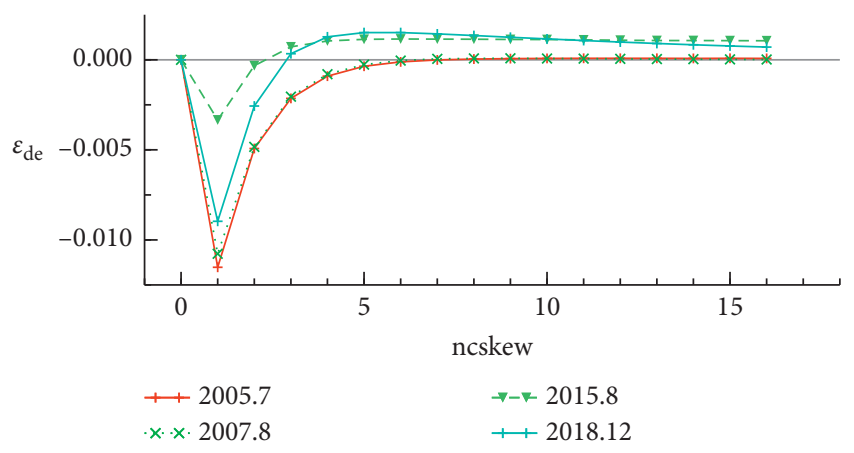

(c)

Figure 4: Continued.

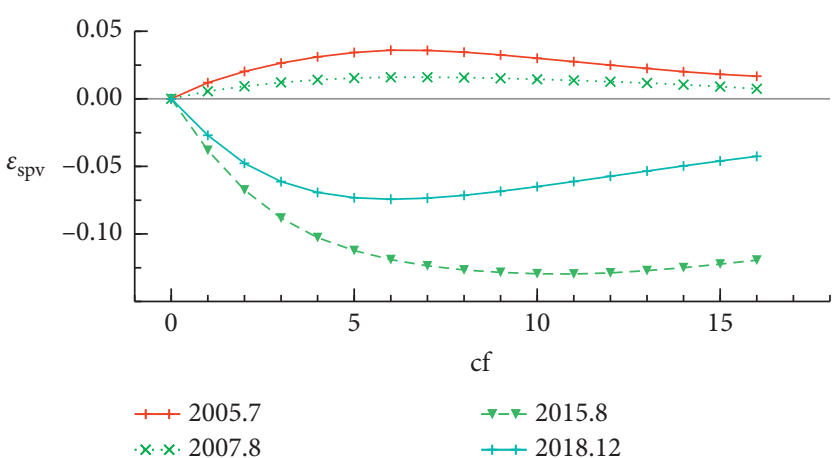

(d) 


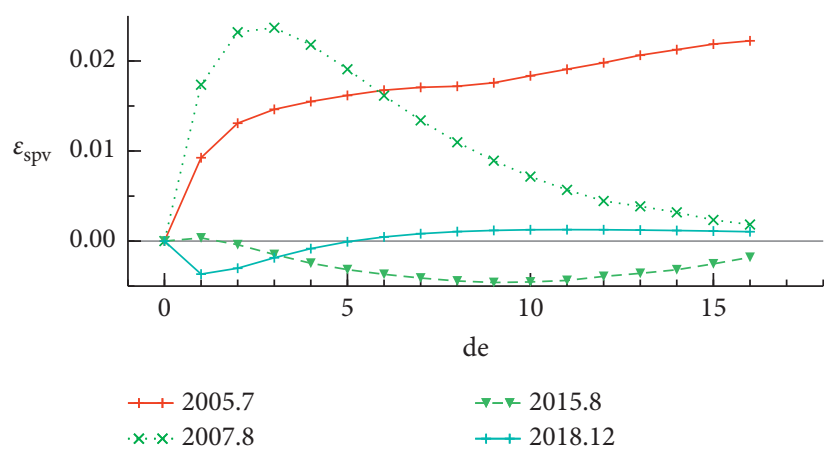

(e)

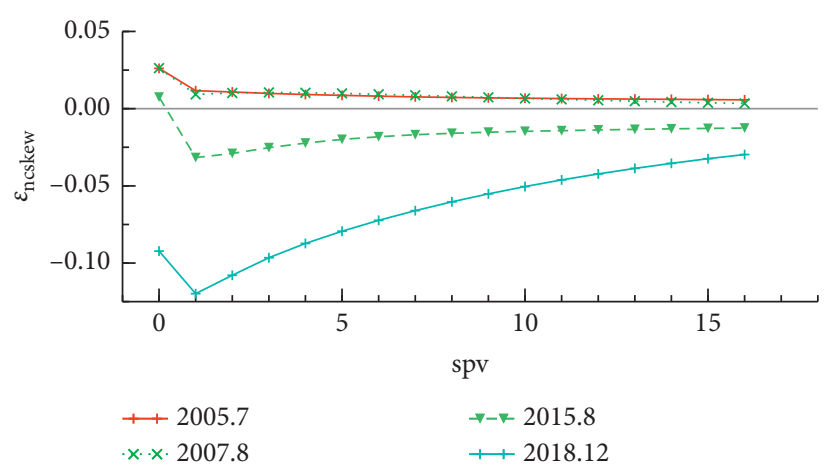

(f)

FIgURE 4: The impulse response of internal shock at different time points.
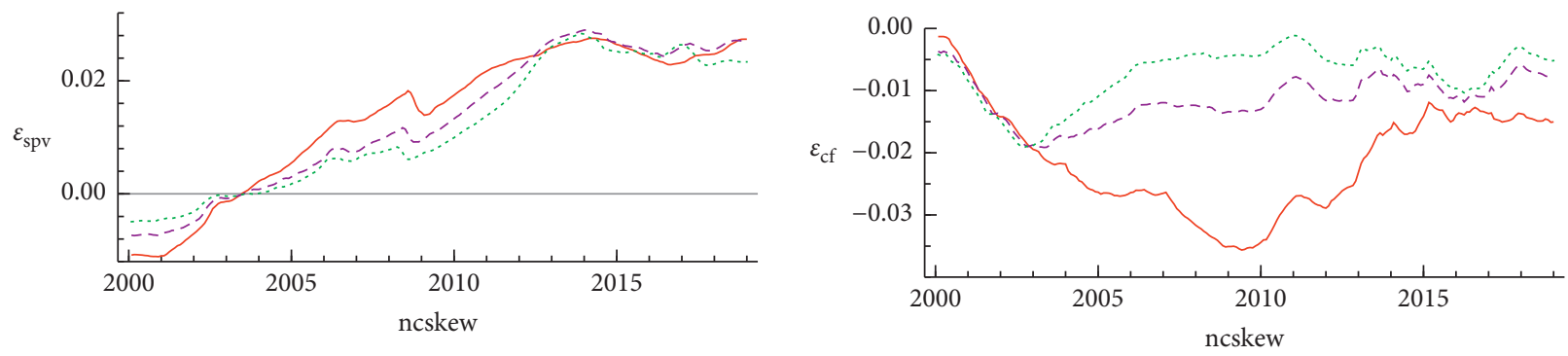

- 1-period ahead

- - 3-period ahead

..... 5-period ahead

- 1-period ahead

-- 3-period ahead

-.... 5-period ahead

(a)

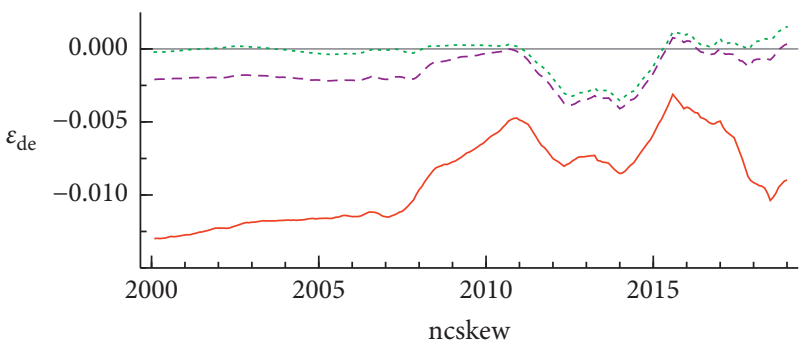

(b)

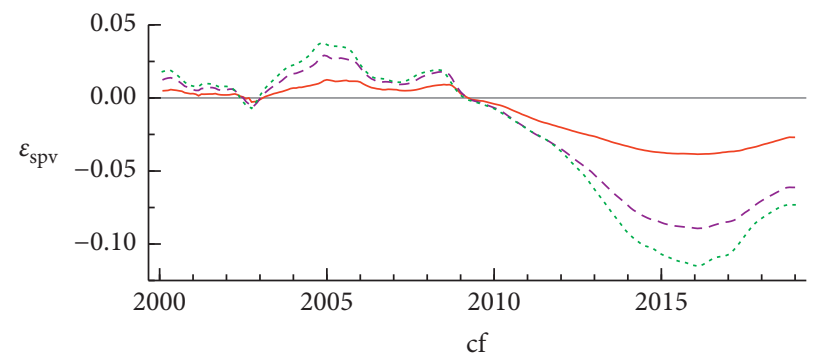

- 1-period ahead

- - 3-period ahead

1-period ahead

- - 3-period ahead

..... 5-period ahead

(c)

(d)
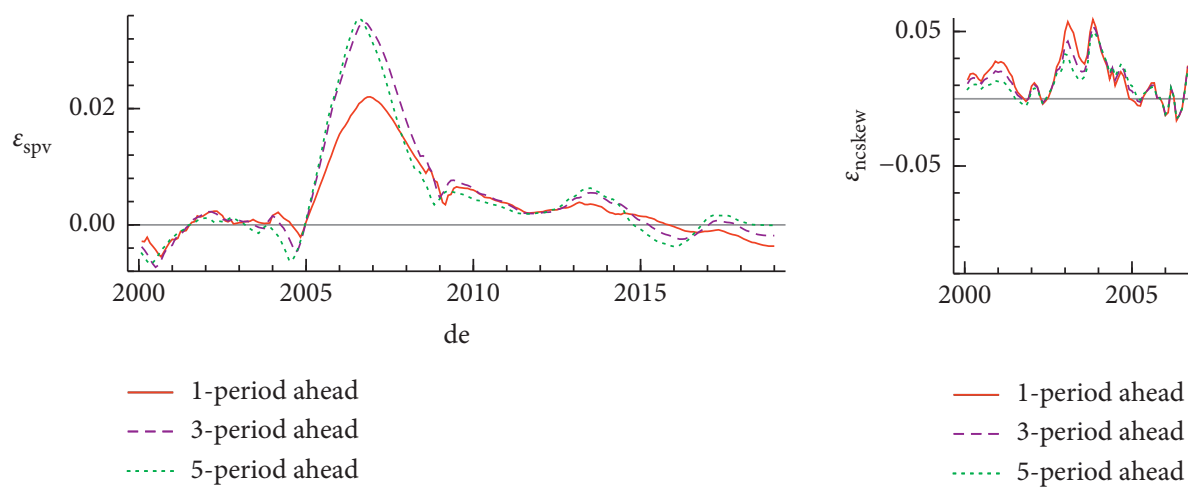

(e)

FIGURE 5: Time-varying impulse responses. 
responses of short-term capital flow are highly consistent. Before the subprime crisis in 2007, the impulse responses of short-term capital flow were relatively small. But after the subprime crisis, short-term capital flow declined significantly, and the impulse responses of short-term capital flow are more obvious for 3 months and 5 months ahead. When the shocks of S\&P 500 volatility for 1 month, 3 months, and 5 months ahead are positive, the impulse responses of RMB exchange rates are positive in 2005-2009 and fluctuate up and down near 0 in the other years. When the shocks of China's stock market crash risk for 1 month, 3 months, and 5 months ahead are positive, the impulse responses of the US stock volatility are highly consistent. And, 2010 marks a watershed because US stock volatility increased China's stock market crash risk before 2010 but decreased it after 2010, which may be due to the increase of global economic uncertainty and the flight to quality.

To summarize, from the time-varying impulse response analysis, we can conclude that US stock volatility increases China's stock market crash risk, and the impact strengthens gradually. With the opening of China's financial market, short-term capital outflow and exchange rate depreciation increase China stock market crash risk, and the impact of short-term capital outflow is more significant. The impact of US stock volatility on short-term capital flow appears after the subprime crisis in 2007, and the long-term impact is significant. US stock volatility only affects the exchange rate during the subprime crisis in 2007. The impact of China's stock market crash risk on US stock volatility has changed after 2010 and it is likely due to the opening of China's financial market, allowing short-term capital to flow out of China easier and realize the flight to quality.

5.5. Robustness Test. In this paper, we first replace China's stock market crash with down-to-up volatility (DUVOL) for another empirical analysis, and the results are highly consistent with the negative coefficient of skewness (NCSKEW). Then, we replace S\&P 500 volatility (SPV) with Dow Jones industrial average volatility (DJIAV) and get the same results. In addition, we use the unconditional volatility of the US stock for the robust check, and we obtain similar results. We also use the real effective exchange rate (REER) for the robust check, and we obtain consistent results. Therefore, our results are robust.

\section{Conclusion}

We used the TVP-VAR model to study the linkage between US stock volatility and China's stock market crash risk, including the impulse response at different time points and time-varying impulse responses and analyzed the dynamic spillover effects between US stock volatility and China's stock market crash risk under the time-varying framework. Our findings show that the US stock volatility has obvious time-varying impacts on China's stock market crash risk and the impacts are gradually strengthening. When the US stock market fluctuates significantly, China's stock market crash risk increases, the short-term capital will flow from China, and the RMB will devaluate. Moreover, the short-term capital outflow and RMB devaluation will increase China's stock market crash risk, and the impact of short-term capital outflow is more significant. After the subprime crisis in 2007, China's stock market crash risk will reduce the US stock volatility, which may be caused by the flight to quality.

\section{Data Availability}

All data were taken from the CSMAR, Wind, and CEInet statistics databases.

\section{Conflicts of Interest}

The authors declare that they have no conflicts of interest.

\section{Acknowledgments}

This research was supported in part by Beijing Municipal Education Commission Research Program under Grant no. SM202010038007, Beijing Office for Philosophy and Social Sciences Program under Grant no. 16JDYJB026, Capital University of Economics and Trade Beijing Municipal Universities Basic Scientific Research Fund under Grant no. QNTD202004, and NSF of China under Grant no. 71903136.

\section{References}

[1] T. A. Rietz, "The equity risk premium a solution," Journal of Monetary Economics, vol. 22, no. 1, pp. 117-131, 1988.

[2] R. J. Barro, "Rare disasters and asset markets in the twentieth century," Quarterly Journal of Economics, vol. 121, no. 3, pp. 823-866, 2006.

[3] T. Bollerslev and V. Todorov, "Tails, fears, and risk premia," The Journal of Finance, vol. 66, no. 6, pp. 2165-2211, 2011.

[4] X. Gabaix, "Variable rare disasters: an exactly solved framework for ten puzzles in macro-finance," The Quarterly Journal of Economics, vol. 127, no. 2, pp. 645-700, 2012.

[5] N. Gennaioli, A. Shleifer, and R. Vishny, "Neglected risks: the psychology of financial crises," American Economic Review, vol. 105, no. 5, pp. 310-314, 2015.

[6] B. Kelly and H. Jiang, "Tail risk and asset prices," The Review of Financial Studies, vol. 27, no. 10, pp. 2841-2871, 2014.

[7] M. R. C. Van Oordt and C. Zhou, "Systematic tail risk," Journal of Financial and Quantitative Analysis, vol. 51, no. 2, pp. 685-705, 2016.

[8] F. Chabi-Yo, S. Ruenzi, and F. Weigert, "Crash sensitivity and the cross-section of expected stock returns," Journal of Financial and Quantitative Analysis (JFQA), vol. 53, no. 3, 2018.

[9] P. F. Diamandis, "Financial liberalization and changes in the dynamic behaviour of emerging market volatility: evidence from four Latin American equity markets," Research in International Business and Finance, vol. 22, no. 3, pp. 362-377, 2008.

[10] T. Korkmaz, E. İ. Çevik, and E. Atukeren, "Return and volatility spillovers among CIVETS stock markets," Emerging Markets Review, vol. 13, no. 2, pp. 230-252, 2012.

[11] X. Li and B. Zhang, "Spillover and cojumps between the U.S. And Chinese stock markets," Emerging Markets Finance and Trade, vol. 49, no. S2, pp. 23-42, 2013.

[12] Y. Hou and S. Li, "Information transmission between U.S. and China index futures markets: an asymmetric DCC GARCH approach," Economic Modelling, vol. 52, pp. 884-897, 2016. 
[13] H. Asgharian, W. Hess, and L. Liu, "A spatial analysis of international stock market linkages," Journal of Banking \& Finance, vol. 37, no. 12, pp. 4738-4754, 2013.

[14] W. Mensi, S. Hammoudeh, J. C. Reboredo, and D. K. Nguyen, "Do global factors impact BRICS stock markets? A quantile regression approach," Emerging Markets Review, vol. 19, pp. 1-17, 2014.

[15] F. X. Diebold and K. Yilmaz, "Measuring financial asset return and volatility spillovers, with application to global equity markets," The Economic Journal, vol. 119, no. 534, pp. 158-171, 2009.

[16] J. Chevallier, D. K. Nguyen, J. Siverskog, and G. S. Uddin, "Market integration and financial linkages among stock markets in Pacific Basin countries," Journal of Empirical Finance, vol. 46, pp. 77-92, 2018.

[17] F. X. Diebold and K. Yilmaz, "Better to give than to receive: predictive directional measurement of volatility spillovers," International Journal of Forecasting, vol. 28, no. 1, pp. 57-66, 2012.

[18] L. Yang and S. Hamori, "Spillover effect of US monetary policy to ASEAN stock markets: evidence from Indonesia, Singapore, and Thailand," Pacific-Basin Finance Journal, vol. 26, pp. 145-155, 2014.

[19] A. Koulakiotis, A. Kiohos, and V. Babalos, "Exploring the interaction between stock price index and exchange rates: an asymmetric threshold approach," Applied Economics, vol. 47, no. 13, pp. 1273-1285, 2015.

[20] M. Bahmani-Oskooee and S. Saha, "Do exchange rate changes have symmetric or asymmetric effects on stock prices?" Global Finance Journal, vol. 31, pp. 57-72, 2016.

[21] L. Sui and L. Sun, Spillover effects between exchange rates and stock prices: Evidence from BRICS around the recent global financial crisis. Research in International Business and $\mathrm{Fi}-$ nance, 36, 459-471, 2016.

[22] A. Morales-Zumaquero and S. Sosvilla-Rivero, "Volatility spillovers between foreign exchange and stock markets in industrialized countries," The Quarterly Review of Economics and Finance, vol. 70, pp. 121-136, 2018.

[23] D. Kim and S. Iwasawa, "Hot money and cross-section of stock returns during the global financial crisis," International Review of Economics \& Finance, vol. 50, pp. 8-22, 2017.

[24] Y. Wei, Q. Yu, J. Liu, and Y. Cao, "Hot money and China's stock market volatility: further evidence using the GARCHMIDAS model," Physica A: Statistical Mechanics and Its Applications, vol. 492, pp. 923-930, 2018.

[25] H. Taguchi, P. Sahoo, and G. Nataraj, "Capital flows and asset prices: empirical evidence from emerging and developing economies," International Economics, vol. 141, pp. 1-14, 2015.

[26] J. B. R. B. Barroso, L. A. P. Da Silva, and A. S. Sales, "Quantitative Easing and Related Capital Flows into Brazil: measuring its effects and transmission channels through a rigorous counterfactual evaluation," Journal of International Money and Finance, vol. 67, pp. 102-122, 2016.

[27] J. Gyntelberg, M. Loretan, and T. Subhanij, "Private information, capital flows, and exchange rates," Journal of International Money and Finance, vol. 81, pp. 40-55, 2018.

[28] C. A. Sims, "Macroeconomics and reality," Econometrica, vol. 48 , no. 1, pp. 1-48, 1980.

[29] T. Cogley and T. J. Sargent, "Evolving post-world war II U.S. Inflation dynamics," NBER Macroeconomics Annual, vol. 16, pp. 331-373, 2001.

[30] T. Cogley and T. J. Sargent, "Drifts and volatilities: monetary policies and outcomes in the post WWII US," Review of Economic Dynamics, vol. 8, no. 2, pp. 262-302, 2005.
[31] G. E. Primiceri, "Time varying structural vector autoregressions and monetary policy," The Review of Economic Studies, vol. 72, no. 3, pp. 821-852, 2005.

[32] X. He, X.-J. Cai, and S. Hamori, "Bank credit and housing prices in China: evidence from a TVP-VAR model with stochastic volatility," Journal of Risk and Financial Management, vol. 11, no. 4, p. 90, 2018

[33] G. V. Moura and M. R. Noriller, "Maximum likelihood estimation of a TVP-VAR," Economics Letters, vol. 174, pp. 78-83, 2019.

[34] M.-J. Zhou, J.-B. Huang, and J.-Y. Chen, "The effects of geopolitical risks on the stock dynamics of China's rare metals: a TVP-VAR analysis," Resources Policy, vol. 68, p. 101784, 2020.

[35] J. Nakajima, M. Kasuya, and T. Watanabe, "Bayesian analysis of time-varying parameter vector autoregressive model for the Japanese economy and monetary policy," Journal of the Japanese and International Economies, vol. 25, no. 3, pp. 225-245, 2011.

[36] J. Chen, H. Hong, and J. C. Stein, "Forecasting crashes: trading volume, past returns, and conditional skewness in stock prices," Journal of Financial Economics, vol. 61, no. 3, pp. 345-381, 2001.

[37] J.-B. Kim, Y. Li, and L. Zhang, "CFOs versus CEOs: equity incentives and crashes," Journal of Financial Economics, vol. 101, no. 3, pp. 713-730, 2011.

[38] J.-B. Kim, Y. Li, and L. Zhang, "Corporate tax avoidance and stock price crash risk: firm-level analysis," Journal of Financial Economics, vol. 100, no. 3, pp. 639-662, 2011.

[39] J. Geweke, Evaluating the Accuracy of Sampling-Based Approaches to the Calculation of Posterior Moments, Vol. 196, Federal Reserve Bank of Minneapolis, Research Department, Minneapolis, MN, USA, 1991. 